\title{
Correction: A six-gene leukemic stem cell score identifies high risk pediatric acute myeloid leukemia
}

\author{
Abdelrahman H. Elsayed - Roya Rafiee - Xueyuan Cao - Susana Raimondi - James R. Downing • Raul Ribeiro • \\ Yiping Fan · Tanja A. Gruber • Sharyn Baker • Jeffery Klco (D) Jeffrey E. Rubnitz • Stanley Pounds (D) \\ Jatinder K. Lamba (iD
}

Published online: 16 April 2020

(c) The Author(s), under exclusive licence to Springer Nature Limited 2020

Correction to: Leukemia

https://doi.org/10.1038/s41375-019-0604-8

Following the publication of this article the authors noted an error in the following sentence which features in the "Discussion" section of the paper.

"pLSC6 though had different coefficients as compared with the original LSC17 score equation, shared four genes DNMT3B, GPR56, CD34, and SOCS2 with LSC17.
Two new genes, SPINK2 and FAM30A were part of the pLSC6 score."

This has now been corrected in the PDF and HTML versions of this paper to read:

"pLSC6 though had different coefficients as compared with the original LSC17 score equation, shared five genes DNMT3B, GPR56, CD34, FAM30A and SOCS2 with LSC17. One new gene, SPINK2 was part of the pLSC6 score". 